\title{
Evaluation of structural valve deterioration and bioprosthetic valve failure utilizing the new European consensus definition in patients undergoing TAVI with first-generation devices: Outcomes beyond 5 years from a single center in Turkey
}

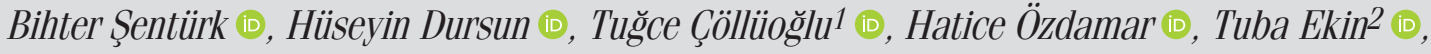 \\ Zülkif Tanrıverdi (D), Dayimi Kaya (1) \\ Department of Cardiology, Faculty of Medicine, Dokuz Eylül University; İzmir-Turkey \\ ${ }^{1}$ Department of Cardiology, Karabük University Training and Research Hospital; Karabük-Turkey \\ ${ }^{2}$ Clinic of Cardiology, Sorgun State Hospital; Yozgat-Turkey \\ ${ }^{3}$ Department of Cardiology, Faculty of Medicine, Harran University; Şanlıurfa-Turkey
}

ABSTRACT

Objective: The long-term durability of transcatheter aortic bioprosthetic valves continues to be a major concern. Standardized criteria of the structural valve deterioration (SVD) and bioprosthetic valve failure (BVF) have recently been defined. Limited studies have evaluated the longterm durability of transcatheter aortic valve implantation (TAVI) according to these new definitions. We aim to analyze the durability of TAVI beyond 5 years and to report the frequency of SVD and BVF.

Methods: A total of 89 patients who had undergone TAVI and had theoretically completed at least 5 years after the procedure were included. Either a Medtronic CoreValve or an Edwards SAPIEN XT valve were implanted in the patients. New standardized definitions were used to evaluate SVD and BVF.

Results: The mean age of the patients was $78.70 \pm 6.95$ years. SVD occured in $4(4.5 \%)$ patients during 6 years of follow-up. Severe SVD was observed in 2 patients $(2.2 \%)$, and these patients had the New York Heart Association class II symptoms. Both patients with severe SVD also met the criteria of BVF. Moderate SVD was observed in 2 patients $(2.2 \%)$, and these patients had no valve-related symptoms. Of the 4 SVD cases, 2 were associated with increased mean transaortic gradients, whereas the remaining 2 cases were associated with intraprosthetic aortic regurgitation. All patients with SVD are still alive, and none of them have required aortic valve reintervention.

Conclusion: Although first-generation TAVI devices were used, we determined the low rate of SVD and BVF at the 6-year follow-up. It may be suggested that there is no major concern associated with TAVI even with first-generation devices regarding long-term durability.

Keywords: heart valves, aortic valve stenosis, transcatheter aortic valve implantation

Cite this article as: Şentürk B, Dursun H, Çöllüoğlu T, Özdamar H, Ekin T, Tanrıverdi Z, et al. Evaluation of structural valve deterioration and bioprosthetic valve failure utilizing the new European consensus definition in patients undergoing TAVI with first-generation devices: Outcomes beyond 5 years from a single center in Turkey. Anatol J Cardiol 2021; 25: 579-87.

\section{Introduction}

Transcatheter aortic valve implantation (TAVI) has emerged as a new treatment alternative for patients with severe symptomatic aortic stenosis (AS) who are at high or prohibitive surgical risk (1). Over time, the development of novel devices and improved techniques has made TAVI safer and easier, which in turn has led to improved patient experience. In addition, studies have shown that TAVI is noninferior $(2,3)$ or superior $(4)$ to surgery in intermediate-risk patients.Therefore, the updated 2017 guidelines adopted a new indication of TAVI for intermediaterisk patients with AS $(5,6)$. Given these favorable outcomes in intermediate-risk patients, TAVI has also recently been offered to be performed in low-risk patients. Meta-analyses including important randomized controlled trials (RCTs) have suggested that TAVI may be an efficient option for subjects at low surgical

Address for Correspondence: Dr. Bihter Şentürk, Dokuz Eylül Üniversitesi Tıp Fakültesi, Kardiyoloji Anabilim Dalı, İmir-Türkiye

Phone: +90 2324124130 E-mail: drbihter@hotmail.com

Accepted Date: 12.04.2021 Available Online Date: 20.06.2021

(C) Copyright 2021 by Turkish Society of Cardiology - Available online at www.anatoljcardiol.com DOI:10.5152/AnatolJCardiol.2021.37670 


\section{HIGHLIGHTS}

- Long-term durability of transcatheter aortic valve implantation (TAVI) is a major concern.

- Standardized criteria of the structural valve deterioration (SVD) and bioprosthetic valve failure (BVF) have recently been defined.

- Limited studies have evaluated the long-term durability of TAVI according to the new definition.

- We determined low rate of SVD and BVF with the first-generation TAVI devices at the 6-year follow-up.

risk $(7,8)$. However, the 2020 American College of Cardiology (ACC)/American Heart Association (AHA) Guideline has emphasized that the mean age of patients with low to moderate surgical risk included in RCTs was over 70 , very few patients were under 65 years of age. Because life expectancy is longer in this particular group than in usual candidates for TAVI, long-term valve durability will gain more importance. Therefore, the 2020 ACC/AHA Guideline has not recommended the use of TAVI in young patients $(<65$ years) except in special cases owing to durability concerns (1).

Structural valve deterioration (SVD) represents a major problem in TAVI. Studies assessing the durability of transcatheter aortic bioprosthetic valves for up to 5 years found low SVD rates (9-12). However, different studies have used different criteria to define SVD, and therefore, it is difficult to make comparisons among studies (9-14). Recently, the standardized definition criteria for SVD and bioprosthetic valve failure (BVF) have been proposed by the European Society of Cardiology, the European Association of Percutaneous Cardiovascular Interventions, and the European Association for Cardio-Thoracic Surgery to generate uniformity in data reporting of next studies evaluating the long-term durability of TAVI (15). There are very few studies evaluating the incidence of SVD and BVF in accordance with these new criteria.

Our clinic is one of the centers where the first TAVI procedures were performed in Turkey. Therefore, we had a chance to follow TAVI patients for a long period. In this study, we aimed to present our long-term clinical experience of TAVI and to report the frequency of SVD and BVF according to the European standardized criteria in TAVI patients who completed at least 5-year follow-up.

\section{Methods}

\section{Patient selection}

A total of 89 consecutive patients who had undergone TAVI for severe AS between June 2012 and June 2015 and had theoretically completed at least 5 years after the procedure were included in this study. All patients were at high or prohibitive surgical risk for surgical valve replacement. A multidisciplinary heart team evaluated the patients, and the same experienced team performed all TAVI procedures. The decision of TAVI was taken following the existing guideline (16). The operative risk was measured using the logistic European System for Cardiac Operative Risk Evaluation (EuroSCORE), EuroSCORE II, and Society of Thoracic Surgeons (STS) score (17-19). Before TAVI, all patients underwent detailed imaging analyses including transthoracic echocardiography (TTE), transesophageal echocardiography (TEE), computed tomography (CT), and coronary with peripheral angiography. The TEE and CT images were used to assess the aortic valve, annulus, degree of calcification, and ascending aorta. The patients who needed revascularization, revascularization was performed before TAVI.

\section{Data collection}

All patients' baseline clinical characteristics, mortality and morbidity rates, and long-term follow-up records were investigated in a retrospective way. The data of the patients were obtained from our hospital records, the Ministry of Health, and/ or by interviewing the participants by phone. The approval for this research was acquired from the Ethics Committee.

\section{Echocardiographic evaluation}

All subjects underwent a standard TTE before and after TAVI (the first day after TAVI, before discharge, and 1, 2, 3, 4, 5, and 6 years after TAVI) using a Philips HD11 XE cardiac ultrasound machine (Philips HD11XE, SONOS 4500, Andover, MA, USA). All echocardiographic and Doppler measurements were performed according to the Journal of the American Society of Echocardiography guidelines (20). The echocardiographic data described as post-TAVI in this article were predischarge echocardiographic values. The severity of the paravalvular leak (PVL) and intraprosthetic aortic regurgitation (AR) was assessed as suggested by the American Society of Echocardiography and the European Association of Echocardiography guidelines in the following way: absent or trace as grade 0 , mild as grade 1 , moderate as grade 2 , severe as grade $\geq 3(21)$.

\section{TAVI procedure}

All TAVI procedures were performed in the catheter laboratory by applying general or local anesthesia with deep sedation. We used a balloon-expandable Edwards SAPIEN XT valve (ESV) (Edwards Lifesciences, Irvine, CA, USA) or a self-expandable Medtronic CoreValve (MCV, Minneapolis, MN, USA). After the implantation procedure, we evaluated $A R$, valve position, and coronary artery blood flow using aortic root angiography. Afterward, the closure of the peripheral entry site was performed, and control angiography was conducted.

\section{Patient follow-up}

In-hospital and long-term complications were assessed according to the Valve Academic Research Consortium 2 (VARC2) criteria (22). Antiplatelet therapy with aspirin and clopidogrel was administered for at least 6 months after TAVI. Single or dual (according to the bleeding risk) antiplatelet therapy 
combined with oral anticoagulants was administered for 3 months after TAVI in patients who must take oral anticoagulants because of any reason. After their general condition stabilized, patients were discharged from the hospital and scheduled for follow-up visits after 1 month, 3 months, 6 months, 1 year, and then annually. During follow-up visits, the patients' functional capacities and the results of routine physical investigations, echocardiograms, and laboratory tests were assessed. We were in communication with all patients on the phone: some patients could not come to the hospital for echocardiographic evaluation due to advanced age, debility, and multiple comorbidities. There were 30 patients with a minimum 5 years of echocardiographic data and 14 patients with 6 years of echocardiographic data.

\section{Definitions of SVD and BVF}

The SVD and BVF were assessed according to the new standardized European definition (15). Moderate hemodynamic SVD was defined as follows: (1) mean aortic valve gradient (MG) $\geq 20$ and $<40 \mathrm{~mm} \mathrm{Hg}$ and/or $\geq 10$ and $<20 \mathrm{~mm} \mathrm{Hg}$ variation from the baseline (before discharge or within 30 days of valve implantation) and/or (2) moderate new or worsening $(>1+/ 4+)$ intraprosthetic AR. Severe hemodynamic SVD was defined as follows: (1) $M G \geq 40$ and/or $\geq 20 \mathrm{~mm} \mathrm{Hg}$ variation from the baseline (before discharge or within 30 days of valve implantation) and/or (2) severe new or worsening $(>2+/ 4+)$ intraprosthetic AR. BVF was defined as any of following: (1) autopsy evidence of bioprosthetic valve dysfunction that was possibly associated with the cause of death, or valve-related death (in other words, a death that is caused by bioprosthetic valve dysfunction or sudden unexplained death after the diagnosis of bioprosthetic valve dysfunction), (2) reintervention (eg, valve-in-valve TAVI, PVL closure, or surgical aortic valve replacement) after the verified diagnosis of bioprosthetic valve dysfunction, and (3) severe hemodynamic SVD (15).

\section{Statistical analysis}

The data analysis was performed with the SPSS 22.0 software program (IBM SPSS Statistics for Windows, Version 22.0., IBM Corp, Armonk, NY, USA). The assumption of normality was tested by the Kolmogorov-Smirnov test. Continuous variables with a normal distribution were expressed as mean \pm standard deviation, whereas those with a non-normal distribution were expressed as median [01-03]. Categorical variables were presented as number and percentages. Pre-TAVI and post-TAVI variables were compared with Wilcoxon signed-rank test. Repeated measurements were compared with Friedman test for nonparametric variables: "aortic valve area" or "mean gradient." The estimation of survival rates was performed, and these were plotted by the Kaplan-Meier method. The assessment of the findings was performed at a $95 \%$ confidence interval and the $p<0.05$ significance level.

\section{Results}

A total of 89 patients with a mean age of $78.7 \pm 6.95$ years were enrolled in this study. All patients had tricuspid aortic

\begin{tabular}{|c|c|}
\hline Variables & Values \\
\hline Age, years & $78.70 \pm 6.95$ \\
\hline Female gender (\%) & $55(61.8)$ \\
\hline Logistic EuroSCORE (\%) & $31.03 \pm 12.61$ \\
\hline EuroSCORE II (\%) & $4.63(3.57-6.69)$ \\
\hline STS score $(\%)$ & $6.8(4.07-10.55)$ \\
\hline NYHA Class III and IV (\%) & $63(70.8)$ \\
\hline \multicolumn{2}{|l|}{ Comorbidities } \\
\hline Hypertension (\%) & $78(87.6)$ \\
\hline Diabetes mellitus (\%) & $29(32.6)$ \\
\hline Atrial fibrillation (\%) & $23(25.8)$ \\
\hline COPD (\%) & $28(31.5)$ \\
\hline Previous history of CABG (\%) & $19(21.3)$ \\
\hline Previous history of valve surgery (\%) & $4(4.5)$ \\
\hline Coronary artery disease $(\%)$ & $34(38.2)$ \\
\hline Prior pacemaker (\%) & $3(3.4)$ \\
\hline \multicolumn{2}{|l|}{ Echocardiographic variables } \\
\hline LVEF, \% & $58.5(38.5-60)$ \\
\hline Transaortic peak gradient, mm Hg & $73(62-87)$ \\
\hline Transaortic mean gradient, $\mathrm{mm} \mathrm{Hg}$ & $46(40-53)$ \\
\hline AVA, $\mathrm{cm}^{2}$ & $0.56(0.47-0.7)$ \\
\hline Moderate/Severe AR (\%) & $16(18)$ \\
\hline sPAP, mm Hg & $45(35-60)$ \\
\hline \multicolumn{2}{|c|}{$\begin{array}{l}\text { AR - aortic regurgitation; AVA - aortic valve area; CABG - coronary artery bypass } \\
\text { grafting; COPD - chronic obstructive pulmonary disease; EuroSCORE - European Systen } \\
\text { for Cardiac Operative Risk Evaluation; LVEF - left ventricular ejection fraction; NYHA - } \\
\text { New York Heart Association; SPAP - systolic pulmonary artery pressure; STS - Society } \\
\text { of Thoracic Surgeons }\end{array}$} \\
\hline
\end{tabular}

valve. The median follow-up duration was 45.5 months (13.867.3). The mean Logistic EuroSCORE and median STS score were $31.03 \pm 12.61$ and 6.8 (4.07-10.55), respectively (Table 1). Procedural characteristics of the study are presented in Table 2. The TAVI procedure was conducted via transfemoral access route in all patients. Surgical cutdown was used in $96.6 \%$ of the patients, whereas percutaneous access was used in $3.4 \%$ of the patients via ProStar XL10Fr or Perclose Proglide vascular closure devices (Abbott Vascular Devices, Redwood City, California, USA). In total, $64 \%$ (57) of implanted valves were MCV, and $36 \%$ (32) were ESV.

Echocardiographic variables before and after TAVI are shown in Table 3. A significant decrease was observed in the transaortic peak gradient, MG, and systolic pulmonary artery pressure (sPAP), whereas a significant increase was observed in aortic valve area (AVA) and left ventricular ejection fraction after TAVI (Table 3). The detailed change in MG and AVA according to the valve types during follow-up are depicted in Figure 1a-c. During the 6 years of follow-up, no significant 


\begin{tabular}{|c|c|}
\hline Variables & Values \\
\hline \multicolumn{2}{|c|}{ Femoral access route (\%) } \\
\hline Surgical cut down & $86(96.6)$ \\
\hline Percutaneous closure & $3(3.4)$ \\
\hline \multicolumn{2}{|l|}{ Implanted valves (\%) } \\
\hline Medtronic CoreValve & $57(64)$ \\
\hline $23 \mathrm{~mm}$ & $2(2.2)$ \\
\hline $26 \mathrm{~mm}$ & $15(16.9)$ \\
\hline $29 \mathrm{~mm}$ & $30(33.7)$ \\
\hline $31 \mathrm{~mm}$ & $10(11.2)$ \\
\hline Edwards SAPIEN XT & $32(36)$ \\
\hline $23 \mathrm{~mm}$ & $14(15.8)$ \\
\hline $26 \mathrm{~mm}$ & $15(16.9)$ \\
\hline $29 \mathrm{~mm}$ & $3(3.4)$ \\
\hline Predilatation (\%) & $87(97.8)$ \\
\hline Postdilatation (\%) & $2(2.2)$ \\
\hline
\end{tabular}

Table 3. Echocardiographic data before and after TAVI

\begin{tabular}{|lccc|}
\hline & Pre-TAVI & Post-TAVI & $P$-value \\
\hline LVEF (\%) & $58.5(38.5-60)$ & $60(50-64)$ & $<0.001$ \\
$\begin{array}{l}\text { Transaortic peak } \\
\text { gradient, mm Hg }\end{array}$ & $73(62-87)$ & $15(11-20)$ & $<0.001$ \\
$\begin{array}{l}\text { Transaortic mean } \\
\text { gradient, mm Hg }\end{array}$ & $46(40-53)$ & $8(5.8-9)$ & $<0.001$ \\
$\begin{array}{l}\text { AVA, cm } 2 \\
\text { SPAP, mm Hg }\end{array}$ & $0.56(0.47-0.7)$ & $1.73(1.49-2.01)$ & $<0.001$ \\
\hline $\begin{array}{l}\text { AVA - aortic valve area; LVEF - left ventricular ejection fraction; sPAP - systolic } \\
\text { pulmonary artery pressure; TAVI - transcatheter aortic valve implantation }\end{array}$ & \\
\hline
\end{tabular}

change was determined in AVA and MG in the whole group (Fig. 1a), in the MCV group (Fig. 1b), and in the ESV group (Fig. 1c). The comparison of MG and AVA between the MCV and ESV groups during the follow-up is shown in Figure $2 \mathrm{a}$ and $2 \mathrm{~b}$. The patients in the MCV group had significantly lower MG compared with the patients in the ESV group $(p<0.001)$ (Fig. 2a). However, AVA was similar between the 2 groups during 6 years of follow-up ( $p=0.927$ ) (Fig. 2b).

Post-TAVI complications according to the VARC-2 criteria are presented in Table 4. Vascular complications were observed in $13(14.6 \%)$ patients, pericardial tamponade in $2(2.2 \%)$ patients, stroke in $1(1.1 \%)$ patient, and ventricular septal rupture in 1 $(1.1 \%)$ patient. Moderate PVL was observed in $5(5.6 \%)$ patients before discharge. However, it was observed that moderate PVL decreased over time. In the first-year evaluation, moderate PVL was determined in only 1 patient. No patient had moderate or severe PVL during the second-, third-, fourth, fifth-, and sixthyear controls. Furthermore, in-hospital mortality developed in only 2 patients owing to sepsis.

\begin{tabular}{|lc|}
\hline \multicolumn{2}{|l|}{$\begin{array}{l}\text { Table 4. Complication of transcatheter aortic valve implantation } \\
\text { according to the VARC-2 criteria (n=89) }\end{array}$} \\
\hline Variables & Values \\
\hline Bleeding (\%) & $6(6.7)$ \\
Life-threatening or disabling bleeding & $17(19.1)$ \\
Major bleeding & $11(12.4)$ \\
Minor bleeding & $13(14.6)$ \\
Vascular complication (\%) & $0(0)$ \\
Coronary obstruction (\%) & $0(0)$ \\
Annular rupture (\%) & $5(5.6)$ \\
$\geq$ Moderate paravalvular leak (\%) & \\
Acute kidney injury (\%) & $8(8.9)$ \\
Stage 1 & $3(3.4)$ \\
Stage 2 & $0(0)$ \\
Stage 3 & $13(14.6)$ \\
Permanent pacemaker (\%) & $2(2.2)$ \\
Pericardial tamponade (\%) & $1(1.1)$ \\
Stroke (\%) & $1(1.1)$ \\
Ventricular septal rupture (\%) & $2(2.2)$ \\
In-hospital mortality (\%) & \\
\hline vaRC-2 - Valve Academic Research Consortium 2 & \\
\hline
\end{tabular}

\section{SVD and BVF}

SVD developed in $4(4.5 \%)$ patients during the 6-year follow-up (MCV: 1 patient, ESV: 3 patients). A total of $2(2.2 \%)$ patients had moderate SVD, whereas 2 patients had severe SVD according to the echocardiography. These 2 patients with severe SVD also met the BVF criteria, and therefore, the frequency of BVF was found to be $2.2 \%$. In the first patient with severe SVD (patient \#1) (i.e., BVF \#1), MG increased to $40 \mathrm{~mm}$ $\mathrm{Hg}$ from baseline of $18 \mathrm{~mm} \mathrm{Hg}$ in the third-year control. The patient had a $23 \mathrm{~mm}$ ESV and presented with the New York Heart Association (NHYA) class II symptoms. MGs were 42, 41, and $42 \mathrm{~mm} \mathrm{Hg}$ during the fourth-, fifth-, and sixth-year control, respectively. In the second patient with severe SVD (patient \#2) (i.e., BVF \#2), new severe (3+/4+) intraprosthetic AR with 26 $\mathrm{mm}$ ESV was detected in the fifth-year control. The patient presented with NHYA class II symptoms, and there was no increase in intraprosthetic $A R$ in the sixth-year control. As there were no severe symptoms and hemodynamic compression, these 2 patients did not require any reintervention and were followed-up with medical therapy. In the first patient with moderate SVD (patient \#3), MG increased to $21 \mathrm{~mm} \mathrm{Hg}$ from baseline of $10 \mathrm{~mm} \mathrm{Hg}$ with $26 \mathrm{~mm}$ ESV in the fourth-year control. The patient had no valve-related symptoms. MG remained stable and did not increase in the fifth- and sixth-year controls. New moderate $(2+/ 4+)$ intraprosthetic AR with $29 \mathrm{~mm}$ MCV was detected in the second patient with moderate SVD (patient \#4) during the fourth-year control. This patient had no valverelated symptoms, and there was no increase in intrapros- 

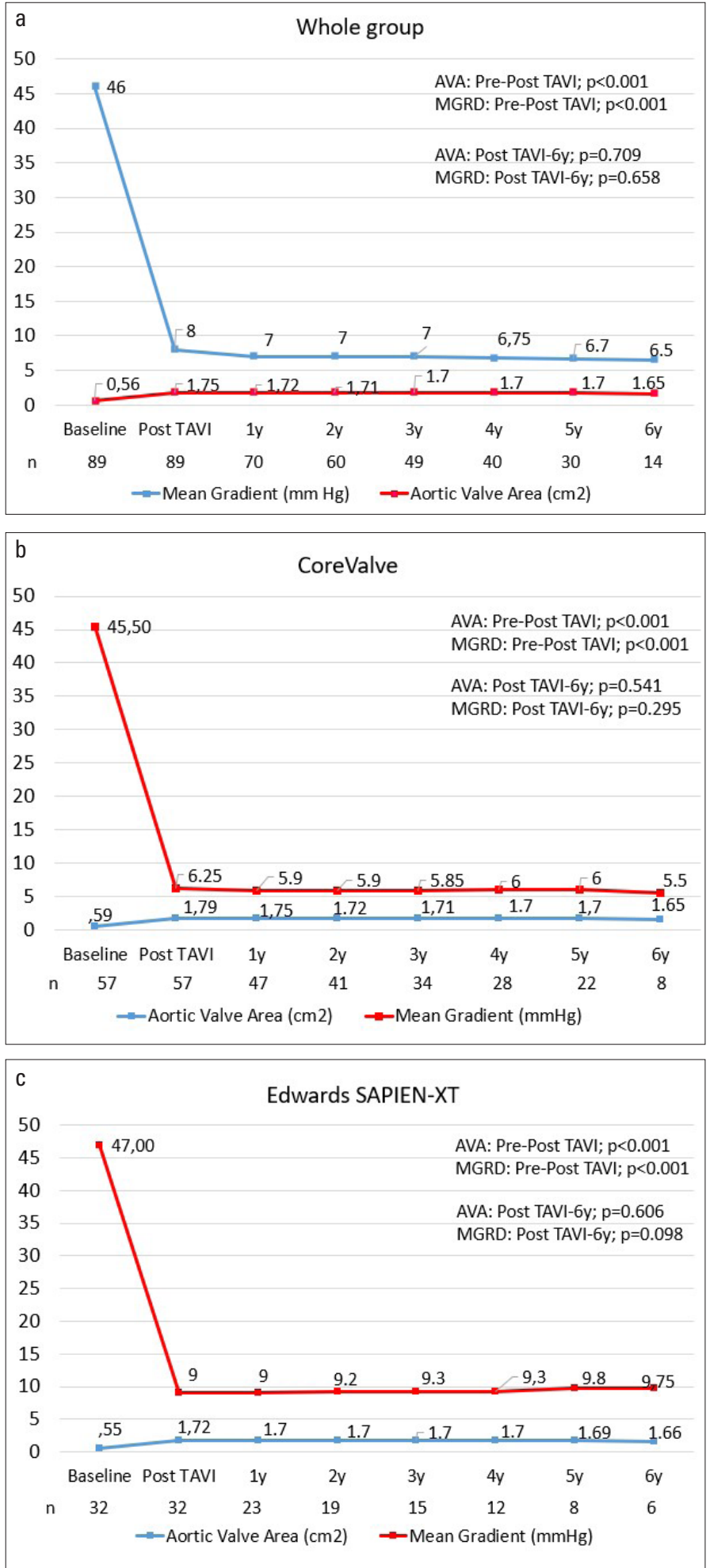

Figure 1. Changes in the mean gradient and aortic valve area during follow-up in the (a) whole group, (b) CoreValve group, and (c) Edwards SAPIEN group

thetic AR during the fifth-year control. As these 2 patients were asymptomatic, they were followed-up without requiring any intervention. No deaths were observed in these 4 patients with SVD, and all of them are still alive.
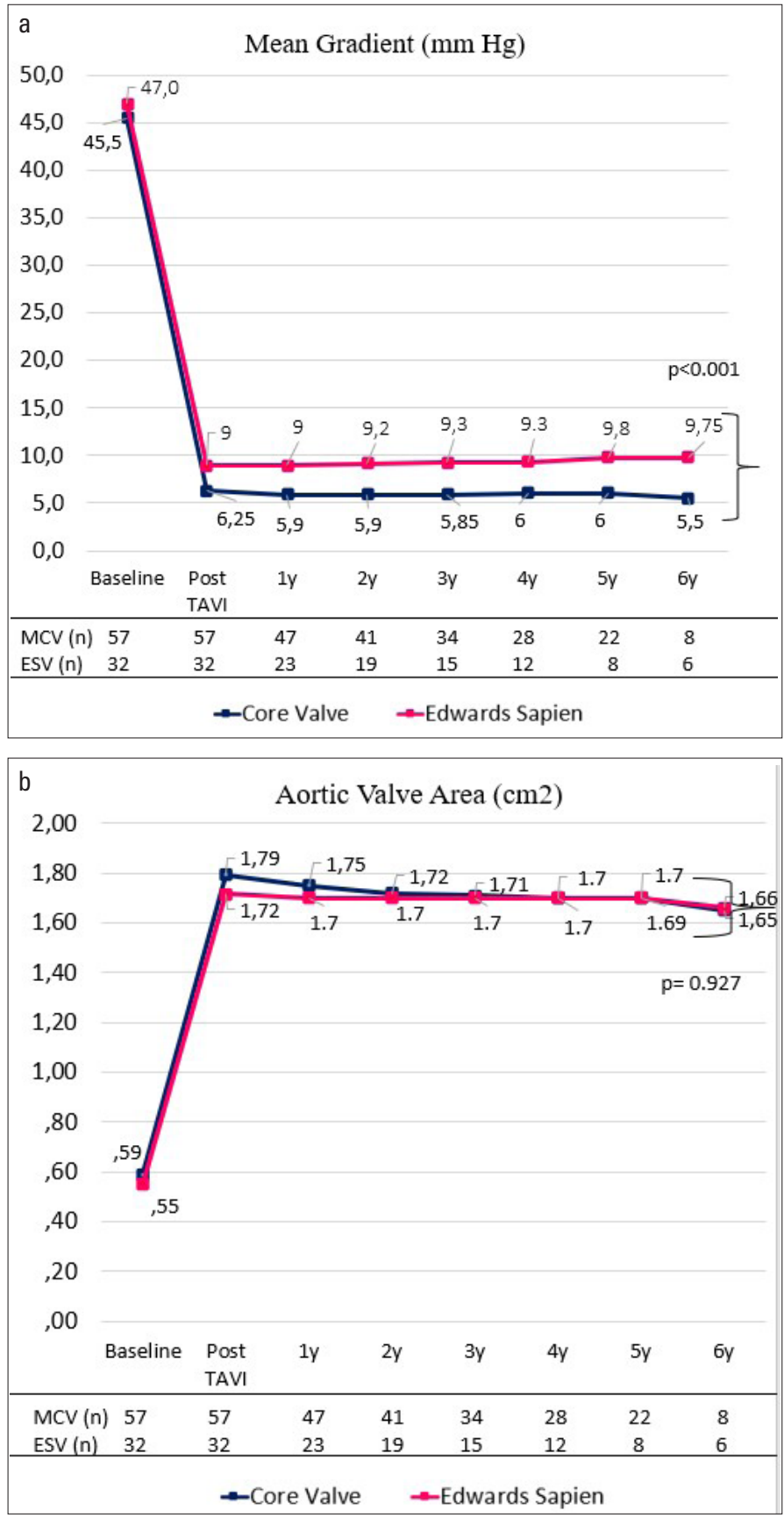

Figure 2. Comparison of the (a) mean gradient and (b) aortic valve area between the CoreValve and Edwards SAPIEN groups during follow-up

\section{Survival}

A total of 49 patients died during the 6-year follow-up. Survival rates at 1 to 6 years according to the Kaplan-Meier analysis were $86.5 \%, 77.5 \%, 68.5 \%, 60.6 \%, 51.7 \%$, and $45 \%$, respectively (Fig. 3). No death was attributed to SVD and/or BVF.

\section{Discussion}

In this study, we aimed to reveal SVD and BVF frequency according to the new standardized European definitions in patients with a minimum of 5 years completed after TAVI. The 


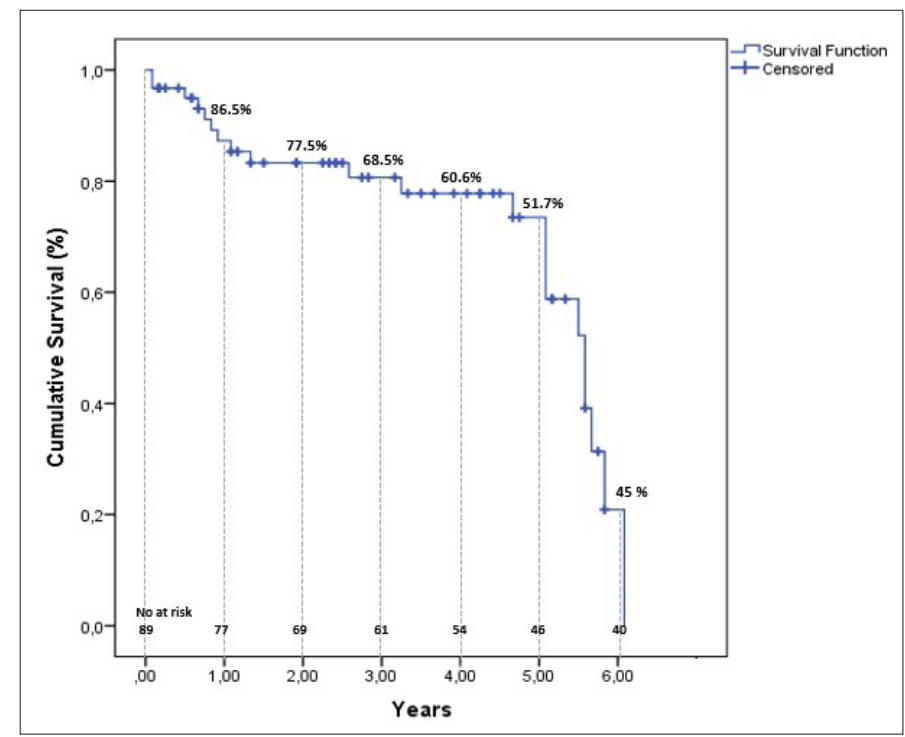

Figure 3. Survival rates according to the Kaplan-Meier analysis

main finding of our study was that SVD developed in only 4 $(4.5 \%)$ patients [2 of them (2.2\%) also defined as BVF] during the 6 -year follow-up. In addition, although valve hemodynamics remained stable over time, the patients in the MCV group had significantly lower mean transaortic gradients in comparison with the patients in the ESV group during follow-up. To the best of our knowledge, this is the first study evaluating SVD and BVF using the New European Consensus Definition in patients undergoing TAVI with first-generation devices in Turkey.

As the duration of implanted transcatheter aortic bioprosthetic valves increases, long-term valve durability and dysfunction become a more serious concern. Therefore, studies assessing the long-term durability of bioprosthetic valves have started to gain more importance. Although the initial TAVI studies reported the durability of valve up to 5 years, data regarding the frequency of SVD and long-term durability are limited. No significant increases in the MG or evidence of SVD were detected during the 5-year follow-up of the PARTNER I trial (11). The Canadian TAVI multicenter registry findings were also consistent with the findings of the PARTNER 1 trial (23). Moreover, 2 studies presented outcomes following TAVI with the Edwards SAPIEN or CoreValve bioprosthesis up to 5 years, no major doubt regarding the durability of transcatheter aortic bioprosthetic valves were noted, with stable $M G$ and low rates of $\operatorname{SVD}(9,10)$. Furthermore, in a recent meta-analysis including 13 pooled studies, the incidence of SVD was 28 per 10,000 patients/year. SVD was not found to be frequent within the first 5 years after TAVI (24). However, the most important limitations of these mentioned studies were that SVD definitions used in these studies were extremely heterogeneous, and there was no an agreed and standardized criteria to define SVD. Therefore, it is difficult to make comparisons among studies. We think that the definitions and incidence of SVD in previous studies need to be updated.

Recently, the standardized European definitions of SVD and BVF for evaluating the long-term durability of transcatheter and surgical aortic bioprosthetic valves have been reported (15). The aim of this new definition is to provide consistency in the reporting of long-term durability of both transcatheter and surgical valves. This new definition focuses not only on survival and/or reoperation as used by surgeons but also on clinical implications of SVD and enables more precise and universal evaluation of SVD. Studies evaluating the frequency of SVD according to the currently available standardized European definitions are very limited. Eltchaninoff et al. (25) assessed the incidence of SVD and BVF using these new definitions in patients who had undergone the TAVI procedure with a balloon-expandable valve. They found that the incidence of SVD and BVF at 8 years was $3.2 \%$ (9 patients) and $0.58 \%$ (2 patients), respectively. Both patients with BVF had severe hemodynamic SVD and required redo TAVI due to the presence of severe symptoms (25). Barbanti et al. (26) also investigated the incidence of SVD and BVF using the new definitions in patients undergoing the TAVI procedure with an MCV or ESV. They observed that the incidence of severe and moderate SVD at 8 years was $2.39 \%$ (7 patients) and $5.87 \%$ (13 patients), respectively. Furthermore, the incidence of BVF at 8 years was $4.5 \%$ (11 patients). Of the BVF patients, 4 had cardiac-related deaths, whereas 7 of them had severe hemodynamic SVD in mentioned study. Only 2 patients with severe hemodynamic SVD required reintervention, and the remaining patients did not need any additional invasive treatment (26). In our study, the frequency of severe and moderate hemodynamic SVD was only $2.2 \%$ (2 patients) and $2.2 \%$ (2 patients), respectively. Two patients with severe SVD also met the BVF criteria, and there were no patients with BVF except these 2 patients. Patients with severe SVD (also defined as BVF) had only mild symptoms (NYHA class II) and did not develop hemodynamic compression. Furthermore, MG and intraprosthetic AR did not increase during follow-up in these patients. Moreover, these 2 patients were older adults ( 80 and 85 years old) and not very active physically. Therefore, they did not require any additional intervention (including redo TAVI). If these patients were younger, more active physically, had severe symptoms, and/or hemodynamic compression, we would perform reintervention. Similar to our study, Barbanti et al. (26) did not perform redo TAVI in 5 of 7 severe SVD cases because they were asymptomatic. They performed redo TAVI in only 2 patients with symptomatic severe SVD. Eltchaninoff et al. (25) also performed redo TAVI in patients with symptomatic progressive severe SVD. Although the optimal management of severe SVD and/or BVF is currently a matter of debate, redo TAVI seems to be a safe and feasible treatment option (27). The decision of reintervention in patients with severe SVD is based on several factors, including age, comorbidities, risk of intervention, patient's preference, type of valve failure, anatomical structure, and local experience (28). However, it has been stated that redo TAVI is generally required when nonreversible symptoms or hemodynamic compression develop (29). In a recent registry evaluating patients who underwent redo TAVI at 37 centers, the frequency of redo TAVI has been found as $0.33 \%$ ( 212 of 63,876 TAVI patients). It is noteworthy that $80 \%$ of patients who underwent redo TAVI had severe symptoms (NYHA classes III and IV) (30). We think that the decision of redo 
TAVI requires a multidisciplinary team approach, and the presence of progressive/severe symptoms or hemodynamic compression are the most important factors.

Although no data are currently available, in vitro studies suggest that the possible mechanisms of increased risk of SVD may be suboptimal leaflet coaptation due to incomplete expansion of transcatheter valve, asymmetrical frame expansion, and leaflet injury after crimping and ballooning of the valve $(31,32)$. Nevertheless, the possible structural damage on the crimped leaflet and its effect on valve durability are hypothetical (33).

Previous studies demonstrated that MCV implantation was related to better hemodynamic performance than ESV implantation. It was observed that maximum and MG were significantly lower and the effective orifice area was significantly larger with an MCV compared with an ESV (34-37). In this study, both valves demonstrated significant decreases in MG following TAVI, and $M G$ remained low and stable over time. However, similar to these studies, we also found that the MCV group had significantly lower MG compared with the ESV group during the follow-up. The main reason for a better hemodynamic performance of MCV may be due to its self-expandable features with higher compliance. In addition, supra-annular placement of leaflet may provide lower resistance and better valve function $(38,39)$. Postprocedural higher gradients may predispose to early degeneration of valve leaflets. However, it is unclear whether the increased gradient following TAVI causes a more accelerated valve deterioration. Indeed, the fact that both patients with stenotic SVD had higher postprocedural MG (both with ESV) suggest that post-TAVI increased gradients may be associated with SVD in our study (patients \#1 and \#3). We think that further studies with larger participant are required to better elucidate the relationship between increased post-TAVI gradients and SVD.

It has been reported that patient-related factors such as systemic diseases, chronic kidney disease (CKD), higher calcium-phosphorus product, and hyperparathyroidism may also play a role in the development of SVD (40). It was remarkable that both patients with SVD associated with the new intraprosthetic AR had CKD in this study (patients \#2 and \#4). In a previous study, it was found that the prevalence of aortic valve calcification was increased in patients with CKD (41). These results suggest that the cause of SVD in these 2 patients may be related to leaflet calcification caused by CKD.

PVL is a common complication after TAVI. The incidence of PVL after TAVI has been reported to be between $7 \%$ and $24 \%$. However, it has been demonstrated that its frequency decreases over time (36). In the new standardized definition, PVL has not been regarded as SVD, and it was defined as nonstructional deterioration. In this study, moderate PVL was observed in $5.6 \%$ of patients before discharge. However, no patients had moderate or severe PVL after 2 years. These improvement observed in PVL were similarly observed in the previous studies $(42,43)$.

\section{Study limitations}

Our study had some limitations. The primary limitations of our study was the low number of patients from a single center and its retrospective design. Second, we had some patients without echocardiographic control data due to advanced age, debility, and/or multiple comorbidities. The COVID-19 pandemic may also be a reason for the lack of control echocardiography data due to a decrease in admission to the hospital. However, we already were in communication with these patients, and they reported no complaints related to SVD. We considered that they would have been admitted to the hospital if they felt any discomfort. Third, SVD and BVF were evaluated by echocardiography in our study. Although echocardiography is superior for the demonstration of valve hemodynamics, performing multidetector CT to evaluate the morphological structure of the bioprosthetic valve and to define morphological SVD could further contribute to our study. Finally, because of the small population and low number of patients with SVD, we could not compare MCV and ESV in terms of the frequency of SVD. We believe that further prospective and larger studies evaluating the hemodynamic \& morphological SVD and comparing SVD rates according to the bioprosthetic valve types are required.

\section{Conclusion}

The durability of transcatheter aortic bioprosthetic valves remains a major concern. Although first-generation TAVI devices were used in this study, we determined the low rate of SVD and BVF at the 6-year follow-up. Therefore, it may be suggested that there is no major concern associated with transcatheter aortic bioprosthetic valves with regard to long-term durability, even with the first-generation devices.

Conflict of interest: None declared.

Peer-review: Externally peer-reviewed.

Authorship contributions: Concept - B.Ş., H.D., T.Ç., H.Ö., T.E., Z.T., D.K.; Design - B.Ş., H.D, T.Ç., H.Ö., T.E., Z.T., D.K; Supervision - B.Ş., H.D., T.Ç., H.Ö., T.E., Z.T., D.K; Fundings - None; Materials - B.Ş., H.D., T.Ç., H.Ö.,T.E.; Data collection and/or processing - B.Ş., H.Ö., T.E.; Analysis and/or interpretation - B.S.,, H.D., T.Ç., H.Ö., T.E., Z.T., D.K.; Literature Review - B.Ş., H.D., T.Ç., Z.T., D.K.; Writing - B.Ş., T.Ç., Z.T., D.K.; Critical Review - B.Ş., H.D., Z.T., D.K.

\section{References}

1. Otto CM, Nishimura RA, Bonow RO, Carabello BA, Erwin JP 3rd, Gentile F, et al. 2020 ACC/AHA Guideline for the Management of Patients With Valvular Heart Disease: Executive Summary: A Report of the American College of Cardiology/American Heart Association Joint Committee on Clinical Practice Guidelines. Circulation 2021; 143: e35-71. [Crossref]

2. Leon MB, Smith CR, Mack MJ, Makkar RR, Svensson LG, Kodali SK, et al. Transcatheter or Surgical Aortic-Valve Replacement in IntermediateRisk Patients. N Engl J Med 2016; 374: 1609-20. [Crossref]

3. Reardon MJ, Van Mieghem NM, Popma JJ, Kleiman NS, Søndergaard L, Mumtaz M, et al.; SURTAVI Investigators. Surgical or Transcatheter Aortic-Valve Replacement in Intermediate-Risk Patients. N Engl J Med 2017; 376: 1321-31. [Crossref] 
4. Thourani VH, Kodali S, Makkar RR, Herrmann HC, Williams M, Babaliaros $\mathrm{V}$, et al. Transcatheter aortic valve replacement versus surgical valve replacement in intermediate-risk patients: a propensity score analysis. Lancet 2016; 387: 2218-25. [Crossref]

5. Nishimura RA, Otto CM, Bonow RO, Carabello BA, Erwin JP 3rd, Fleisher LA, et al. 2017 AHA/ACC Focused Update of the 2014 AHA/ ACC Guideline for the Management of Patients With Valvular Heart Disease: A Report of the American College of Cardiology/American Heart Association Task Force on Clinical Practice Guidelines. Circulation 2017; 135: e1159-95. [Crossref]

6. Baumgartner H, Falk V, Bax JJ, De Bonis M, Hamm C, Holm PJ, et al.; ESC Scientific Document Group. 2017 ESC/EACTS Guidelines for the management of valvular heart disease. Eur Heart J 2017; 38: 2739-91. [Crossref]

7. Kolte D, Vlahakes GJ, Palacios IF, Sakhuja R, Passeri JJ, Inglessis I, et al. Transcatheter Versus Surgical Aortic Valve Replacement in Low-Risk Patients. J Am Coll Cardiol 2019; 74: 1532-40. [Crossref]

8. Vipparthy SC, Ravi V, Avula S, Kambhatla S, Mahmood M, Kabour A, et al. Meta-Analysis of Transcatheter Aortic Valve Implantation Versus Surgical Aortic Valve Replacement in Patients With Low Surgical Risk. Am J Cardiol 2020; 125: 459-68. [Crossref]

9. Toggweiler S, Humphries KH, Lee M, Binder RK, Moss RR, Freeman $\mathrm{M}$, et al. 5-year outcome after transcatheter aortic valve implantation. J Am Coll Cardiol 2013; 61: 413-9. [Crossref]

10. Barbanti M, Petronio AS, Ettori F, Latib A, Bedogni F, De Marco F, et al. 5-Year Outcomes After Transcatheter Aortic Valve Implantation With CoreValve Prosthesis. JACC Cardiovasc Interv 2015; 8: 108491. [Crossref]

11. Mack MJ, Leon MB, Smith CR, Miller DC, Moses JW, Tuzcu EM, et al. 5-year outcomes of transcatheter aortic valve replacement or surgical aortic valve replacement for high surgical risk patients with aortic stenosis (PARTNER 1): a randomised controlled trial. Lancet 2015; 385: 2477-84. [Crossref]

12. Muratori M, Fusini L, Tamborini G, Gripari P, Ghulam Ali S, Mapelli M, et al. Five-year echocardiographic follow-up after TAVI: structural and functional changes of a balloon-expandable prosthetic aortic valve. Eur Heart J Cardiovasc Imaging 2018; 19: 389-97. [Crossref]

13. Arsalan $\mathrm{M}$, Walther $\mathrm{T}$. Durability of prostheses for transcatheter aortic valve implantation. Nat Rev Cardiol 2016; 13: 360-7. [Crossref]

14. Del Trigo M, Muñoz-Garcia AJ, Wijeysundera HC, Nombela-Franco L, Cheema AN, Gutierrez E, et al. Incidence, Timing, and Predictors of Valve Hemodynamic Deterioration After Transcatheter Aortic Valve Replacement: Multicenter Registry. J Am Coll Cardiol 2016; 67: 644-55. [Crossref]

15. Capodanno D, Petronio AS, Prendergast B, Eltchaninoff $H$, Vahanian A, Modine T, et al. Standardized definitions of structural deterioration and valve failure in assessing long-term durability of transcatheter and surgical aortic bioprosthetic valves: a consensus statement from the European Association of Percutaneous Cardiovascular Interventions (EAPCI) endorsed by the European Society of Cardiology (ESC) and the European Association for Cardio-Thoracic Surgery (EACTS). Eur Heart J 2017; 38: 3382-90. [Crossref]

16. Vahanian A, Alfieri 0 , Andreotti F, Antunes MJ, Barón-Esquivias G, Baumgartner $\mathrm{H}$, et al.; Joint Task Force on the Management of Valvular Heart Disease of the European Society of Cardiology (ESC); European Association for Cardio-Thoracic Surgery (EACTS), Guidelines on the management of valvular heart disease (version 2012). Eur Heart J 2012; 33: 2451-96.
17. Roques F, Michel P, Goldstone AR, Nashef SA. The logistic EuroSCORE. Eur Heart J 2003; 24: 881-2. [Crossref]

18. Nashef SA, Roques F, Sharples LD, Nilsson J, Smith C, Goldstone AR, et al. EuroSCORE II. Eur J Cardiothorac Surg 2012; 41: 734-44. [Crossref]

19. O'Brien SM, Shahian DM, Filardo G, Ferraris VA, Haan CK, Rich JB, et al.; Society of Thoracic Surgeons Quality Measurement Task Force. The Society of Thoracic Surgeons 2008 cardiac surgery risk models: part 2--isolated valve surgery. Ann Thorac Surg 2009; 88 (1 Suppl): S23-42. [Crossref]

20. Zamorano JL, Badano LP, Bruce C, Chan KL, Gonçalves A, Hahn RT, et al. EAE/ASE recommendations for the use of echocardiography in new transcatheter interventions for valvular heart disease. J Am Soc Echocardiogr 2011; 24: 937-65. [Crossref]

21. Zoghbi WA, Chambers JB, Dumesnil JG, Foster E, Gottdiener JS, Grayburn PA, et al.; American Society of Echocardiography's Guidelines and Standards Committee; Task Force on Prosthetic Valves; American College of Cardiology Cardiovascular Imaging Committee; Cardiac Imaging Committee of the American Heart Association; European Association of Echocardiography; European Society of Cardiology; Japanese Society of Echocardiography; Canadian Society of Echocardiography; American College of Cardiology Foundation; American Heart Association; European Association of Echocardiography; European Society of Cardiology; Japanese Society of Echocardiography; Canadian Society of Echocardiography. Recommendations for evaluation of prosthetic valves with echocardiography and doppler ultrasound: a report From the American Society of Echocardiography's Guidelines and Standards Committee and the Task Force on Prosthetic Valves, developed in conjunction with the American College of Cardiology Cardiovascular Imaging Committee, Cardiac Imaging Committee of the American Heart Association, the European Association of Echocardiography, a registered branch of the European Society of Cardiology, the Japanese Society of Echocardiography and the Canadian Society of Echocardiography, endorsed by the American College of Cardiology Foundation, American Heart Association, European Association of Echocardiography, a registered branch of the European Society of Cardiology, the Japanese Society of Echocardiography, and Canadian Society of Echocardiography. J Am Soc Echocardiogr 2009; 22: 975-1014. [Crossref]

22. Kappetein AP, Head SJ, Généreux P, Piazza N, van Mieghem NM, Blackstone $\mathrm{EH}$, et al. Updated standardized endpoint definitions for transcatheter aortic valve implantation: the Valve Academic Research Consortium-2 consensus document. Eur Heart J 2012; 33 : 2403-18. [Crossref]

23. Rodés-Cabau J, Webb JG, Cheung A, Ye J, Dumont E, Osten M, et al. Long-term outcomes after transcatheter aortic valve implantation: insights on prognostic factors and valve durability from the Canadian multicenter experience. J Am Coll Cardiol 2012; 60: 186475. [Crossref]

24. Foroutan F, Guyatt GH, Otto CM, Siemieniuk RA, Schandelmaier S, Agoritsas T, et al. Structural valve deterioration after transcatheter aortic valve implantation. Heart 2017; 103: 1899-905. [Crossref]

25. Eltchaninoff H, Durand E, Avinée G, Tron C, Litzler PY, Bauer F, et al. Assessment of structural valve deterioration of transcatheter aortic bioprosthetic balloon-expandable valves using the new European consensus definition. Eurolntervention 2018; 14: e264-71. [Crossref] 
26. Barbanti M, Costa G, Zappulla P, Todaro D, Picci A, Rapisarda G, et al. Incidence of Long-Term Structural Valve Dysfunction and Bioprosthetic Valve Failure After Transcatheter Aortic Valve Replacement. J Am Heart Assoc 2018; 7: e008440. [Crossref]

27. Barbanti M, Webb JG, Tamburino C, Van Mieghem NM, Makkar RR, Piazza N, et al. Outcomes of Redo Transcatheter Aortic Valve Replacement for the Treatment of Postprocedural and Late Occurrence of Paravalvular Regurgitation and Transcatheter Valve Failure. Circ Cardiovasc Interv 2016; 9: e003930. [Crossref]

28. Attias D, Nejjari M, Nappi F, Dreyfus J, Eleid MF, Rihal CS. How to treat severe symptomatic structural valve deterioration of aortic surgical bioprosthesis: transcatheter valve-in-valve implantation or redo valve surgery? Eur J Cardiothorac Surg 2018; 54: 977-85. [Crossref]

29. D'arrigo P, Capodanno D. Structural valve deterioration and bioprosthetic valve failure. Cardiac Interventions Today 2020; 14: 54-61.

30. Landes U, Webb JG, De Backer O, Sondergaard L, Abdel-Wahab M, Crusius L, et al. Repeat Transcatheter Aortic Valve Replacement for Transcatheter Prosthesis Dysfunction. J Am Coll Cardiol 2020; 75: 1882-93. [Crossref]

31. Barbanti M, Webb JG, Gilard M, Capodanno D, Tamburino C. Transcatheter aortic valve implantation in 2017: state of the art. Eurolntervention 2017; 13: AA11-21. [Crossref]

32. Barbanti $\mathrm{M}$, Tamburino $\mathrm{C}$. Late degeneration of transcatheter aortic valves: pathogenesis and management. Eurolntervention 2016; 12: Y33-6. [Crossref]

33. Alavi SH, Groves EM, Kheradvar A. The effects of transcatheter valve crimping on pericardial leaflets. Ann Thorac Surg 2014; 97: 1260-6. [Crossref]

34. Nombela-Franco L, Ruel M, Radhakrishnan S, Webb JG, Hansen M, Labinaz $M$, et al. Comparison of hemodynamic performance of selfexpandable CoreValve versus balloon-expandable Edwards SAPIEN aortic valves inserted by catheter for aortic stenosis. Am J Cardiol 2013; 111: 1026-33. [Crossref]
35. Watanabe Y, Hayashida K, Yamamoto M, Mouillet G, Chevalier B, Oguri $A$, et al. Transfemoral aortic valve implantation in patients with an annulus dimension suitable for either the Edwards valve or the CoreValve. Am J Cardiol 2013; 112: 707-13. [Crossref]

36. Kaya D, Tanriverdi Z, Dursun H, Colluoglu T. Echocardiographic outcomes of self-expandable CoreValve versus balloon-expandable Edwards SAPIEN XT valves: the comparison of two bioprosthesis implanted in a single centre. Int J Cardiovasc Imaging 2016; 32: 1371-8. [Crossref]

37. Tanriverdi Z, Dursun H, Kaya D. Comparison of echocardiographic results of CoreValve versus Edwards Sapien valves in patients with bicuspid aortic valve. Catheter Cardiovasc Interv 2016; 88: 496-7. [Crossref]

38. Kim SH, Kim HJ, Kim JB, Jung SH, Choo SJ, Chung CH, et al. Supraannular versus intra-annular prostheses in aortic valve replacement: impact on haemodynamics and clinical outcomes. Interact Cardiovasc Thorac Surg 2019; 28: 58-64. [Crossref]

39. Spethmann S, Dreger H, Schattke S, Baldenhofer G, Saghabalyan D, Stangl V, et al. Doppler haemodynamics and effective orifice areas of Edwards SAPIEN and CoreValve transcatheter aortic valves. Eur Heart J Cardiovasc Imaging 2012; 13: 690-6. [Crossref]

40. Costa G, Criscione E, Todaro D, Tamburino C, Barbanti M. Longterm Transcatheter Aortic Valve Durability. Interv Cardiol 2019; 14: 62-9 [Crossref].

41. Rattazzi M, Bertacco E, Del Vecchio A, Puato M, Faggin E, Pauletto $P$. Aortic valve calcification in chronic kidney disease. Nephrol Dial Transplant 2013; 28: 2968-76. [Crossref]

42. Shishido K, Yamanaka F, Ochiai T, Yamabe T, Noguchi K, Ota T, et al. Hemodynamic comparison of CoreValve and SAPIEN-XT TAVI valves in Japanese patients. Heart Vessels 2019; 34: 1674-83. [Crossref]

43. Sawa Y, Torikai K, Kobayashi J, Niinami H, Kuratani T, Maeda K, et al. Midterm Outcomes With a Self-Expandable Transcatheter Heart Valve in Japanese Patients With Symptomatic Severe Aortic Stenosis. Circ J 2017; 81: 1108-15. [Crossref] 